\title{
A conceptual DFT approach towards analysing feasibility of the intramolecular cycloaddition Diels-Alder reaction of triene amide in Lewis acid catalyst
}

\author{
ABDELILAH BENALLOU ${ }^{\mathrm{a}, *}$, HABIB EL ALAOUI EL ABDALLAOUI ${ }^{\mathrm{a}}$ and \\ HOCINE GARMES ${ }^{\mathrm{b}}$ \\ ${ }^{a}$ Chemoinformatics Research and Spectroscopy and Quantum chemistry, Physical Chemistry Laboratory, \\ Faculty of Science El Jadida, Chouaib Doukkali University, B. P. 20, 2300 El Jadida, Morocco \\ bLaboratory of Bio-organic chemistry, Department of Chemistry, Faculty of Science El Jadida, Chouaib \\ Doukkali University, B. P. 20, 2300 El Jadida, Morocco \\ e-mail: abdo_benallou@yahoo.fr
}

MS received 29 February 2016; revised 3 July 2016; accepted 14 July 2016

\begin{abstract}
The effect of Lewis acid catalysts, $\mathrm{TiCl}_{4}$ and $\mathrm{Et}_{2} \mathrm{AlCl}$ on the intramolecular cycloaddition DielsAlder (IMDA) reaction of triene-amide have been studied theoretically using the DFT (Density Functional Theory) at the 6-31G(d,p) level of theory. The results obtained using the polar model of Domingo, electrophilicity, nucleophilicity indices and thermochemistry computations, demonstrate that these catalysts are coordinated with more nucleophilic atoms of diene fragment (nitrogen and oxygen of amide group). These catalysts affect negatively the feasibility of the reaction as well as the physico-chemical parameters of the IMDA reaction of triene-amide.
\end{abstract}

Keywords. Lewis acid; Diels-Alder; DFT; catalyst; reactivity; intramolecular.

\section{Introduction}

The catalysis of Diels-Alder (DA) reaction by Lewis acids received considerable attention on the part of the experimentalists ${ }^{1-3}$ and theoretical chemists. ${ }^{4-9}$ Indeed, Lewis acids do not only improve the rate and speed of the DA reaction, they also help increase the high regioselectivity and stereoselectivity compared to the uncatalyzed reactions. ${ }^{5,6}$ The first report of catalysis of the DA reaction by Lewis acid appeared in 1960, and $a b$ initio studies or application of density functional theory (DFT) on the role of Lewis acids in the DA reaction began to appear in $1990 .{ }^{4}$ Garcia et al. ${ }^{7}$ have made DFT calculations (B3LYP) to study the role of Lewis acid $\left(\mathrm{BF}_{3}\right)$ in the DA reaction between butadiene and acrolein. The results obtained in these studies have confirmed that the method B3LYP/6-31G(d) is an excellent compromise between computational cost and accuracy of the theoretical study Xia et al., ${ }^{10}$ also studied the impact of $\mathrm{AlCl}_{3}, \mathrm{BCl}_{3}, \mathrm{FeCl}_{3}, \mathrm{COCl}_{2}, \mathrm{CuCl}_{2}, \mathrm{CuCl}$, and $\mathrm{ZnCl}_{2}$ in the DA reaction between isoprene and acrolein by using two chemical methods: Computational and conceptual DFT. ${ }^{11}$ The use of conceptual DFT, based on

*For correspondence the reactivity indices ${ }^{11,12}$ has helped to understand the assessable role of Lewis acids in DA reactions. ${ }^{13-15}$

Currently, Lewis acids of Diethyl Aluminum chloride, $\mathrm{Et}_{2} \mathrm{AlCl}$ and Titanium tetrachloride, $\mathrm{TiCl}_{4}$ are used in the DA reactions for organic synthesis. In this context, the impact of $\mathrm{Et}_{2} \mathrm{AlCl}$ and $\mathrm{TiCl}_{4}$ catalysts are used in the intramolecular Diels-Alder reaction (IMDA) of triene-amide to $25^{\circ} \mathrm{C}$ for the preparation to the Hexahydroindole, which are of interest in chemical and pharmacological industries. ${ }^{16-19}$ This reaction has been widely studied previously under thermal conditions $\left(160^{\circ} \mathrm{C}\right)$ in a nonpolar solvent (first case: toluene $)^{17}$ and in the presence of a polar H-bonding solvent (second case: water) at to $25^{\circ} \mathrm{C} .{ }^{18}$ The studies have shown in the first case that the IMDA reactions of triene-amide are concerted and asynchronous, and giving the exoproduct; in the second case, the reaction is unlikely to take place. In this study, we will try to explain theoretically the possible coordination of $\mathrm{Et}_{2} \mathrm{AlCl}$ and $\mathrm{TiCl}_{4}$ and their role in acceleration of reactivity on the IMDA reactions of triene-amide at ambient temperature (Scheme 1). We have established a greater precision of result with a minimum time of computation in our work on the conceptual DFT. 


\section{Computational Methods}

DFT computations were carried out using the B3LYP ${ }^{20}$ exchange-correlation functional, together with the standard $6-31 \mathrm{G}(\mathrm{d}, \mathrm{p})$ basis set. ${ }^{21}$ The optimizations were carried out using the Berny analytical gradient method. ${ }^{22}$ All computations were carried out with the Gaussian 09 programs. ${ }^{23}$ The global electrophilicity index, $\omega^{24}$ is given by the following expression $(\omega=$ $\mu^{2} / 2 \eta$ ), in terms of the electronic chemical potential, $\mu$ and chemical hardness, $\eta$. Both quantities may be calculated in terms of the one-electron energies of the frontier molecular orbital HOMO and LUMO, as $\varepsilon_{\text {HOMO }}$ and $\varepsilon_{\text {LUMO }}$ such as: $\mu=\left(\varepsilon_{\text {HOMO }}+\varepsilon_{\text {LUMO }}\right) / 2$ and $\eta=\left(\varepsilon_{\text {LUMO }}-\varepsilon_{\text {HOMO }}\right)$, respectively. ${ }^{25}$ The nucleophilicity index, $\mathrm{N}^{26}$ based on the HOMO energies has been obtained within the Kohn-Sham scheme ${ }^{27}$ and defined as: $\mathrm{N}=\left(\mathrm{E}_{\mathrm{Hомо}}(\mathrm{Nu})-\mathrm{E}_{\mathrm{HOMO}}(\mathrm{TCE})\right)$. The nucleophilicity is referred to tetracyanoethylene (TCE), because it presents the lowest HOMO energy in a large series of molecules which already investigated in the context of polar cycloadditions.

The local nucleophilicity, $\mathrm{N}_{\mathrm{k}},{ }^{28}$ is defined as the product of the global nucleophilic index $\mathrm{N}$ and nucleophilic Fukui index $f_{\mathrm{k}}^{-}$.

Thus, $\mathrm{N}_{\mathrm{k}}=\mathrm{N} f_{\mathrm{k}}^{-}$with $\mathrm{N}=\sum \mathrm{N}_{\mathrm{k}}$. The condensed Fukui functions in a molecule with $\mathrm{N}$ electrons was proposed by Yang and Mortier: ${ }^{29}$

$f_{\mathrm{k}}^{+}=\left[\mathrm{q}_{\mathrm{k}}(\mathrm{N}+1)-\mathrm{q}_{\mathrm{k}}(\mathrm{N})\right], \quad$ for nucleophilic attack

$f_{\mathrm{k}}^{-}=\left[\mathrm{q}_{\mathrm{k}}(\mathrm{N})-\mathrm{q}_{\mathrm{k}}(\mathrm{N}-1)\right], \quad$ for electrophilic attack

$q_{\mathrm{k}}(N)$ : Electronic population of the atom $\mathrm{k}$ in the neutral molecule.

$q_{\mathrm{k}}(N+1)$ : Electronic population of the atom $\mathrm{k}$ in the anionic molecule.

$q_{\mathrm{k}}(N-1)$ : Electronic population of the atom $\mathrm{k}$ in the cationic molecule.
We can determine the electrophile $\left(\omega_{\mathrm{F}}\right)$ and nucleophile $\left(\mathrm{N}_{\mathrm{F}}\right)$ indices of fragments ${ }^{30}(\mathrm{~F}=$ diene or dienophile) by the equations given below:

$$
\begin{aligned}
& \omega_{F}=\omega \sum_{k \in F} f_{k}^{+} \\
& N_{F}=N \sum_{K \in F} f_{k}^{-}
\end{aligned}
$$

The calculation of this function has been realized by using the natural of populations analysis (NPA). ${ }^{31}$

\section{Results and Discussion}

\subsection{Possible coordination of Lewis acids ( $\mathrm{TiCl}_{4}$ and $\mathrm{Et}_{2} \mathrm{AlCl}$ ) with atoms in molecule}

The coordination of catalyst in the literature ${ }^{32-34}$ is usually associated with an atom that has lone pairs. Compound Ta $\left(R 1=H, R 2=C_{3}, R 3=H, R 4=\right.$ $\mathrm{CH}_{3}, \mathrm{Z}=\mathrm{CN}$ ) (Scheme 1), has lone pairs in the terminal function of nitrile $(\mathrm{Z}=\mathrm{CN})$ in dienophile fragment (Dp). In addition, another electron-rich carbonyl (CO) of amide function is present in diene fragment (D), so the coordination of Lewis acid is probably done with these groups. Moreover, for compounds $\mathrm{Tb}$ $\left(R 1=H, R 2=H, R 3=H, R 4=C_{3}, Z=\right.$ $\left.\mathrm{CO}_{2} \mathrm{CH}_{3}\right)$ and $\mathrm{Tc}\left(\mathrm{Rl}=\mathrm{CH}_{3}, \mathrm{R} 2=\mathrm{H}, \mathrm{R} 3=\mathrm{H}\right.$, $\mathrm{R} 4=\mathrm{CH}_{3}, \mathrm{Z}=\mathrm{CO}_{2} \mathrm{C}_{2} \mathrm{H}_{5}$ ), the situation is different because of existence of two carbonyl groups (carbonyl (CO) of amide function in diene fragment and carbonyl (CO) of ester function in dienophile fragment). The catalysts have two opportunities for coordination. In order to accelerate or improve the reactivity of the intramolecular reactions, the catalyst must be coordinated with dienophile to decrease LUMO energy and to lower the difference of HOMO-LUMO energy. In the triene-amide molecule, there are three atoms bearing lone pairs (nitrogen and oxygen) distributed between

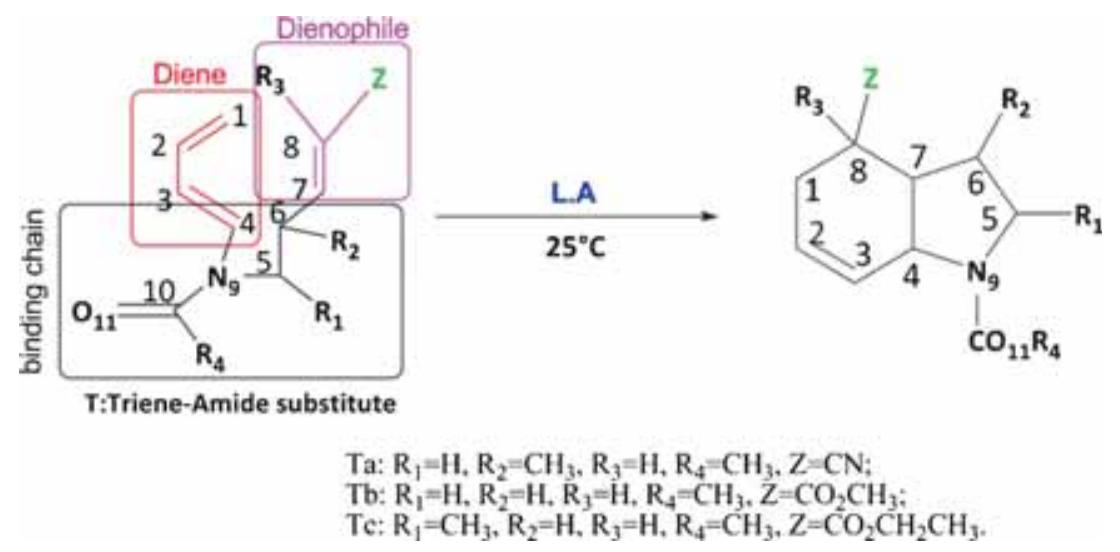

Scheme 1. Intramolecular Diels-Alder reaction of triene-amide catalyzed by Lewis Acid (LA). 
diene and dienophile fragments, and consequently the catalysts have two or three opportunities for coordination of same reagents such as $\mathrm{N}_{9}, \mathrm{O}_{11}, \mathrm{~N}_{13}$ or $\mathrm{O}_{13}$ and $\mathrm{O}_{14}$ (Scheme 1). For adequate coordination, we will try to identify the more nucleophilic atom, using the polar model of Domingo ${ }^{35}$ applied to the ground state; this model requires that a good nucleophile reacts with a good electrophile. In order to know the favorite nucleophile, we apply the theoretical approaches. Lewis acid has an empty square (electrophile) so their coordination will be done to atom with a lone pair (nucleophile). The application of the above equations allows us to calculate the nucleophilicity of each atom $\mathrm{k}\left(\mathrm{k}=\mathrm{N}_{9}, \mathrm{O}_{11}, \mathrm{~N}_{13}\right.$, $\mathrm{O}_{13}$, and $\mathrm{O}_{14}$ ). The results corresponding to the nucleophilic of Fukui index $f_{\mathrm{k}}^{-}$, the global nucleophilicity index $\mathrm{N}$ and the local nucleophilicity index $\mathrm{N}_{\mathrm{K}}$ of atoms $\mathrm{N}_{9}, \mathrm{O}_{11}, \mathrm{~N}_{13}, \mathrm{O}_{13}$ and $\mathrm{O}_{14}$ are reported in Table 1.

Following the results noted in Table 1, Lewis acid is probably making bonding to the nitrogen $\left(\mathrm{N}_{9}\right)$ and oxygen $\left(\mathrm{O}_{11}\right)$ atoms having the greatest nucleophilic power such as, $f^{-}\left(\mathrm{N}_{9}\right)>f^{-}\left(\mathrm{O}_{11}\right)>f^{-}\left(\mathrm{N}_{13}\right)>f^{-}\left(\mathrm{O}_{13}\right)>$ $f^{-}\left(\mathrm{O}_{14}\right)$. Thereby, $\mathrm{N}_{9}$ and $\mathrm{O}_{11}$ atoms of diene fragment are preferable coordination sites. This coordination will possibly not be useful because Lewis acids decrease the reactivity of diene by reducing HOMO energy (nucleophilicity). To explain the possible effects of Lewis acids, we suppose that the catalyst can make coordination on both the nucleophilic atoms. For this reason, we propose studying the two cases of more nucleophilic atoms $\mathrm{O}_{11}$ (case A) and $\mathrm{N}_{9}$ (case B) (Figure 1).

\subsection{Mechanism of intramolecular reaction of triene amide}

In order to know the electronic flux between fragments such as the fragment donor or acceptor of the electron in the intramolecular Diels-Alder reaction, one should calculate the charge transfer (CT) in the transition state of these compounds. To this end, we will assess the two possible cases in the presence of $\mathrm{Et}_{2} \mathrm{AlCl}$ and $\mathrm{TiCl}_{4}$ catalysts and in the gas phase (without catalyst). This is done by using the natural population analysis (NPA), and the results found are given in Table 2.

Table 2 shows that the charge transfer in IMDA reaction for reagents (Ta, $\mathrm{Tb}$ and $\mathrm{Tc}$ ) in the presence and absence of catalysts has taken place from the diene (D)

Table 1. Nucleophilic of Fukui index $f_{k}^{-}$, global nucleophilic index $\mathrm{N}$ and local nucleophilic index $\mathrm{N}_{\mathrm{k}}$ of $\mathrm{N}_{9}, \mathrm{O}_{11}, \mathrm{~N}_{13}, \mathrm{O}_{13}$ and $\mathrm{O}_{14}$ atoms calculated at the 6$31 \mathrm{G}(\mathrm{d}, \mathrm{p}) / / \mathrm{B} 3 \mathrm{LYP}$ level in absence of the catalyst. See Scheme 1 for labels and numbers.

\begin{tabular}{lllcc}
\hline Reagent & \multicolumn{1}{c}{$\mathrm{k}$} & \multicolumn{1}{c}{$f_{k}^{-}$} & $\mathrm{N}(\mathrm{eV})$ & $\mathrm{N}_{\mathrm{k}}(\mathrm{eV})$ \\
\hline $\mathrm{Ta}$ & $\mathrm{O}_{11}$ (Diene fragment) & 0.12627 & 3.29 & 0.800 \\
& $\mathrm{~N}_{9}$ (Diene fragment) & 0.12919 & & $\mathbf{0 . 1 9 0}$ \\
$\mathrm{Nb}$ & $\mathrm{N}_{13}$ (Dienophile fragment) & 0.06216 & & 0.205 \\
& $\mathrm{O}_{11}$ (Diene fragment) & 0.12950 & 3.40 & 0.210 \\
& $\mathrm{~N}_{9}$ (Diene fragment) & 0.12517 & & $\mathbf{0 . 6 2 0}$ \\
& $\mathrm{O}_{13}$ (Dienophile fragment) & 0.01260 & & 0.131 \\
$\mathrm{O}$ & $\mathrm{O}_{14}$ (Dienophile fragment) & $4.8110^{-3}$ & & 0.016 \\
& $\mathrm{O}_{11}$ (Diene fragment) & 0.12112 & 3.21 & 0.210 \\
& $\mathrm{~N}_{9}$ (Diene fragment) & 0.13198 & & $\mathbf{0 . 8 2 0}$ \\
& $\mathrm{O}_{13}$ (Dienophile fragment) & 0.02969 & & 0.102 \\
& $\mathrm{O}_{14}$ (Dienophile fragment) & $4.6110^{-3}$ & & 0.015 \\
\hline
\end{tabular}
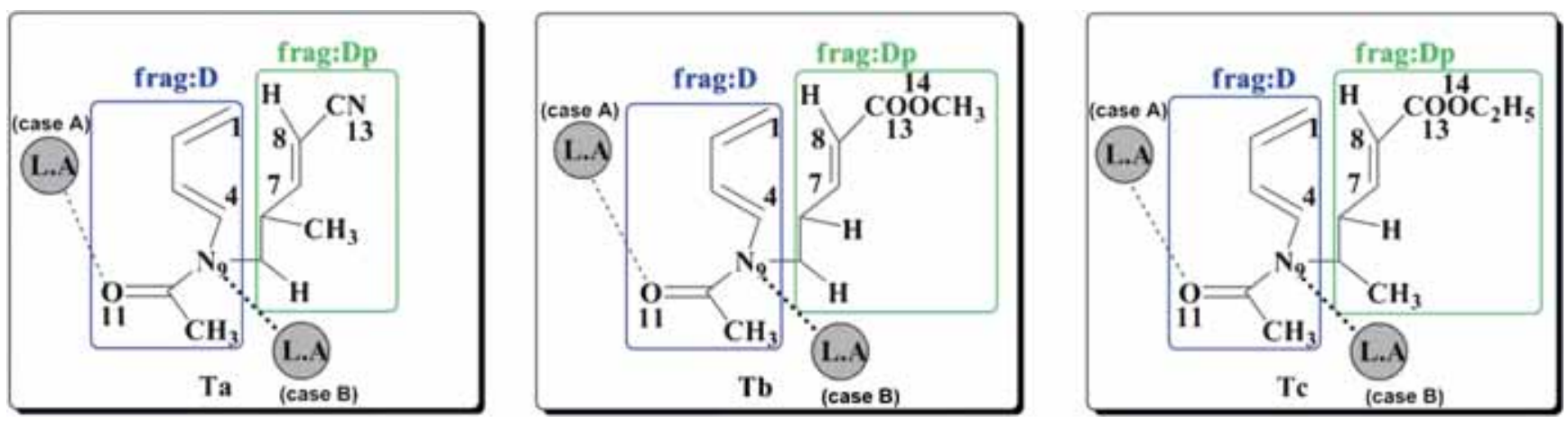

Figure 1. Coordination of Lewis acid by nitrogen and oxygen atoms of amide of the Ta, Tb and Tc compounds. 
Table 2. Charge transfer in $e$ (electronic charge), between diene and dienophile fragments of the transition states in the reactants $\mathrm{Ta}, \mathrm{Tb}$ and $\mathrm{Tc}$.

\begin{tabular}{|c|c|c|c|c|c|c|c|}
\hline \multirow{2}{*}{\multicolumn{2}{|c|}{ Reagent }} & \multicolumn{3}{|c|}{ Diene fragment } & \multicolumn{3}{|c|}{ Dienophile fragment } \\
\hline & & W.C. & $\mathrm{Et}_{2} \mathrm{AlCl}$ & $\mathrm{TiCl}_{4}$ & W.C. & $\mathrm{Et}_{2} \mathrm{AlCl}$ & $\mathrm{TiCl}_{4}$ \\
\hline \multirow[t]{2}{*}{$\mathrm{Ta}$} & Case A & $+0.10 e$ & $+0.065 e$ & $+0.052 e$ & $-0.10 e$ & $-0.065 e$ & $-0.052 e$ \\
\hline & Case B & $+0.10 e$ & $+0.041 e$ & $+0.037 e$ & $-0.10 e$ & $-0.041 e$ & $-0.037 e$ \\
\hline \multirow[t]{2}{*}{$\mathrm{Tb}$} & Case A & $+0.07 e$ & $+0.047 e$ & $+0.032 e$ & $-0.07 e$ & $-0.047 e$ & $-0.032 e$ \\
\hline & Case B & $+0.07 e$ & $+0.038 e$ & $+0.028 e$ & $-0.07 e$ & $-0.038 e$ & $-0.028 e$ \\
\hline \multirow[t]{2}{*}{ Tc } & Case A & $+0.06 e$ & $+0.036 e$ & $+0.029 e$ & $-0.06 e$ & $-0.036 e$ & $-0.029 e$ \\
\hline & Case B & $+0.06 e$ & $+0.017 e$ & $+0.014 e$ & $-0.06 e$ & $-0.017 e$ & $-0.014 e$ \\
\hline
\end{tabular}

+ sign: donor of electron; - sign: acceptor of electron; W.C.: Without catalyst.

Table 3. HOMO and LUMO energies, chemical potential $\mu$, global hardness $\eta$, global softness S, electrophilicity index $\omega$ and nucleophilicity index $\mathrm{N}$ in the presence of the catalyst at $298 \mathrm{~K}$.

\begin{tabular}{|c|c|c|c|c|c|c|c|c|c|}
\hline & Reagent & Catalyst & HOMO (a.u.) & LUMO (a.u.) & $\mu$ (a.u.) & $\eta$ (a.u.) & S (a.u.) & $\omega(\mathrm{eV})$ & $\mathrm{N}(\mathrm{eV})$ \\
\hline \multirow[t]{9}{*}{ CASE A } & \multirow[t]{3}{*}{$\mathrm{Ta}$} & W.C. & -0.21670 & -0.07000 & -0.129 & 0.170 & 2.940 & 1.332 & 3.288 \\
\hline & & $\mathrm{TiCl}_{4}$ & -0.26080 & -0.19300 & -0.203 & 0.114 & 4.160 & 4.918 & 2.024 \\
\hline & & $\mathrm{Et}_{2} \mathrm{AlCl}$ & -0.19650 & -0.08140 & -0.140 & 0.111 & 4.134 & 2.670 & 3.774 \\
\hline & \multirow[t]{3}{*}{$\mathrm{Tb}$} & W.C. & -0.20884 & -0.03716 & -0.123 & 0.172 & 2.910 & 1.197 & 3.400 \\
\hline & & $\mathrm{TiCl}_{4}$ & -0.22129 & -0.11000 & -0.200 & 0.117 & 4.273 & 4.614 & 2.093 \\
\hline & & $\mathrm{Et}_{2} \mathrm{AlCl}$ & -0.20186 & -0.08297 & -0.150 & 0.119 & 4.202 & 2.305 & 3.628 \\
\hline & \multirow[t]{3}{*}{ Tc } & W.C. & -0.20921 & -0.01200 & -0.124 & 0.171 & 2.920 & 1.223 & 3.210 \\
\hline & & $\mathrm{TiCl}_{4}$ & -0.25150 & -0.17700 & -0.198 & 0.113 & 4.180 & 4.720 & 2.203 \\
\hline & & $\mathrm{Et}_{2} \mathrm{AlCl}$ & -0.19821 & -0.07867 & -0.110 & 0.119 & 4.202 & 2.177 & 3.727 \\
\hline \multirow{9}{*}{ CASE B } & \multirow[t]{3}{*}{$\mathrm{Ta}$} & W.C. & -0.21670 & -0.07000 & -0.129 & 0.170 & 2.940 & 1.332 & 3.288 \\
\hline & & $\mathrm{TiCl}_{4}$ & -0.26202 & -0.12030 & -0.210 & 0.105 & 4.775 & 5.711 & 1.991 \\
\hline & & $\mathrm{Et}_{2} \mathrm{AlCl}$ & -0.21682 & -0.07198 & -0.190 & 0.140 & 3.590 & 2.020 & 3.221 \\
\hline & \multirow[t]{3}{*}{$\mathrm{Tb}$} & W.C. & -0.20884 & -0.03716 & -0.123 & 0.172 & 2.910 & 1.197 & 3.400 \\
\hline & & $\mathrm{TiCl}_{4}$ & -0.21908 & -0.11900 & -0.205 & 0.102 & 4.912 & 5.628 & 2.116 \\
\hline & & $\mathrm{Et}_{2} \mathrm{AlCl}$ & -0.22033 & -0.06997 & -0.180 & 0.113 & 3.333 & 1.907 & 3.125 \\
\hline & \multirow[t]{3}{*}{$\mathrm{Tc}$} & W.C. & -0.20921 & -0.01200 & -0.124 & 0.171 & 2.920 & 1.223 & 3.210 \\
\hline & & $\mathrm{TiCl}_{4}$ & -0.20390 & -0.13134 & -0.168 & 0.073 & 6.812 & 5.260 & 3.197 \\
\hline & & $\mathrm{Et}_{2} \mathrm{AlCl}$ & -0.19232 & -0.06261 & -0.127 & 0.130 & 3.890 & 1.688 & 3.888 \\
\hline
\end{tabular}

W.C.: Without catalyst.

to the dienophile (Dp) fragment. Therefore, the diene fragment behaves like electron-releasing (HOMO) and the dienophile fragment behaves like electron-withdrawing (LUMO). Also, the intramolecular cycloaddition Diels-Alder reaction of the triene-amide molecule is controlled by a normal electronic demand in both cases, in the presence and absence of the catalysts. In addition, we have shown that the transfer charge is diminished in compounds catalyzed by Lewis acids, and this can be explained as these catalysts are attractors of charge.

\subsection{Effect of Lewis acid on the global chemical groups}

Lewis acids may change the physico-chemical parameters of the studied compounds, because of their attractive effect on electrons in the case of coordination. Consequently, the new features corresponding to the HOMO and LUMO energies of the diene and dienophile, respectively, chemical potential energy $\mu$, global hardness $\eta$, global softness $\mathrm{S}$, electrophilicity index $\omega$ and nucleophilicity index $\mathrm{N}$ in the presence of $\mathrm{TiCl}_{4}$ and $\mathrm{Et}_{2} \mathrm{AlCl}$ catalysts at $25^{\circ} \mathrm{C}(298 \mathrm{~K})$ are given in Table 3 .

According to this result, we can conclude that the chemical potential $\mu$ become less important in comparison to the uncatalyzed systems. As regards to the electrophilicity index $\omega$, it is known to increase with $\mathrm{TiCl}_{4}$ and $\mathrm{Et}_{2} \mathrm{AlCl}$ catalysts, as well as the nucleophilicity known to decrease with $\mathrm{TiCl}_{4}$ and a slight increase with $\mathrm{Et}_{2} \mathrm{AlCl}$ catalyst $\left(\mathrm{TiCl}_{4}\right.$ is purely electrophilic). Generally, after this result, the electrophilicity increases and the nucleophilicity reduces, thus the Lewis acids are electron withdrawing. 
Table 4. Regional electrophilicity $\left(\omega_{\mathrm{D}}, \omega_{\mathrm{Dp}}\right)$ and regional nucleophilicity $\left(\mathrm{N}_{\mathrm{D}}, \mathrm{N}_{\mathrm{DP}}\right)$ of diene and dienophile fragments.

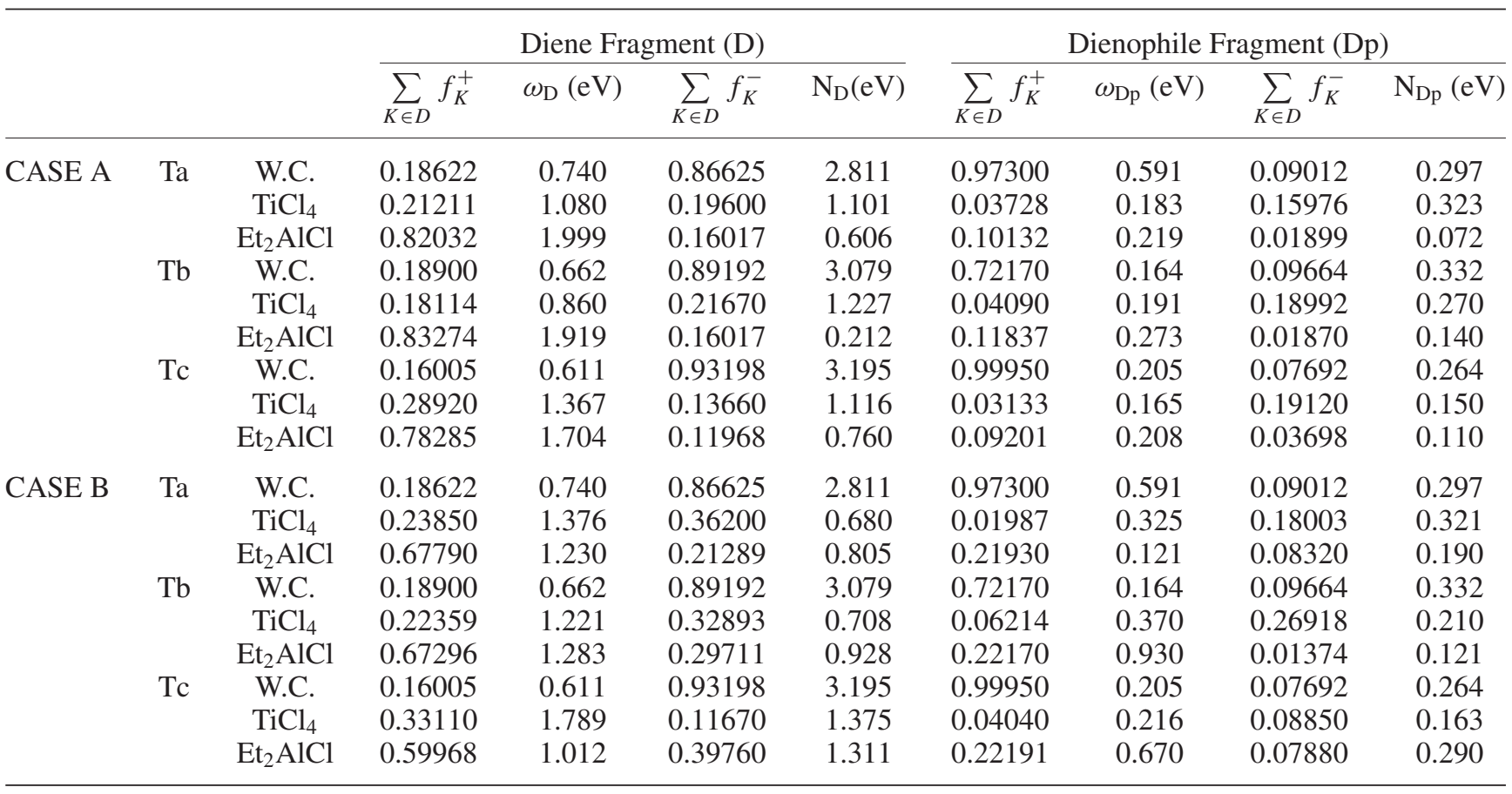

Table 5. Activation energy $E_{a}$, free energy $\Delta G$ and the heat of formation $\Delta H$ of IMDA reaction of $\mathrm{Ta}, \mathrm{Tb}$ and $\mathrm{Tc}$ compounds at $25^{\circ} \mathrm{C}$.

\begin{tabular}{|c|c|c|c|c|c|}
\hline & & & $E_{a}(\mathrm{kcal} / \mathrm{mol})$ & $\Delta G_{r}(\mathrm{kcal} / \mathrm{mol})$ & $\Delta H_{r}(\mathrm{kcal} / \mathrm{mol})$ \\
\hline \multirow[t]{9}{*}{ CASE A } & \multirow[t]{3}{*}{$\mathrm{Ta}$} & W.C. & 29.8 & -11.8 & -19.3 \\
\hline & & $\mathrm{TiCl}_{4}$ & 32.3 & -10.2 & -16.1 \\
\hline & & $\mathrm{Et}_{2} \mathrm{AlCl}$ & 30.9 & -10.9 & -18.1 \\
\hline & \multirow[t]{3}{*}{$\mathrm{Tb}$} & W.C. & 27.9 & -12.2 & -20.1 \\
\hline & & $\mathrm{TiCl}_{4}$ & 30.9 & -10.7 & -17.2 \\
\hline & & $\mathrm{Et}_{2} \mathrm{AlCl}$ & 29.0 & -11.1 & -18.6 \\
\hline & \multirow[t]{3}{*}{ Tc } & W.C. & 26.1 & -15.3 & -24.0 \\
\hline & & $\mathrm{TiCl}_{4}$ & 28.9 & -14.2 & -19.8 \\
\hline & & $\mathrm{Et}_{2} \mathrm{AlCl}$ & 27.6 & -15.1 & -20.2 \\
\hline \multirow[t]{9}{*}{ CASE B } & \multirow[t]{3}{*}{$\mathrm{Ta}$} & W.C. & 29.8 & -11.8 & -19.3 \\
\hline & & $\mathrm{TiCl}_{4}$ & - & 55.7 & 52.9 \\
\hline & & $\mathrm{Et}_{2} \mathrm{AlCl}$ & - & 37.8 & 37.9 \\
\hline & \multirow[t]{3}{*}{$\mathrm{Tb}$} & W.C. & 27.9 & -12.2 & -20.1 \\
\hline & & $\mathrm{TiCl}_{4}$ & - & 66.2 & 61.4 \\
\hline & & $\mathrm{Et}_{2} \mathrm{AlCl}$ & - & 65.3 & 61.9 \\
\hline & \multirow[t]{3}{*}{$\mathrm{Tc}$} & W.C. & 26.1 & -15.3 & -23.9 \\
\hline & & $\mathrm{TiCl}_{4}$ & - & 42.2 & 19.0 \\
\hline & & $\mathrm{Et}_{2} \mathrm{AlCl}$ & - & 11.8 & 33.3 \\
\hline
\end{tabular}

— : not found; W.C.: without catalyst

Subsequently, in presence of these catalysts, the reactivity decreases. This is explained by the chemical potential results such as: $\mu$ (uncatalyzed) $>\mu\left(\mathrm{Et}_{2} \mathrm{AlCl}\right)$ $>\mu\left(\mathrm{TiCl}_{4}\right)$. Nevertheless, the nucleophilic and electrophilic groups of intramolecular reaction do not give deep explanations of inter-fragment reactivity.

In order to know the impact of catalysts to the chemical reactivity of diene and dienophile fragments of IMDA reaction, we will try to identify the nucleophilicity and electrophilicity of diene and dienophile fragments towards these catalysts (Figure 1). The results are given in Table 4.

Following the results in Table 4, we note that the electrophilicity and nucleophilicity characters of diene fragment are changed in the presence of $\mathrm{TiCl}_{4}$ and $\mathrm{Et}_{2} \mathrm{AlCl}$ catalysts. We observe again an increase of electrophilicity and a decrease of nucleophilicity. Therefore, these catalysts play a role of attractor of electrons in diene 
fragment. In addition, the electrophilicity of dienophile fragment decreases for both catalysts and nucleophilicity increases for $\mathrm{TiCl}_{4}$ and slightly decreases for $\mathrm{Et}_{2} \mathrm{AlCl}$. Hence, the effect of $\mathrm{TiCl}_{4}$ catalyst on the IMDA reaction is large compared to $\mathrm{Et}_{2} \mathrm{AlCl}$. So, the nucleophilicity and electrophilicity of diene and dienophile fragments, respectively, will be changed negatively by the Lewis acid.

Consequently, the catalysts decrease the electron donating power of diene fragment and decrease the electron withdrawing power of dienophile fragment, accordingly decreasing the chemical reactivity.

\subsection{Effect of Lewis acid on the energy barriers}

Lewis acids are known for their catalytic power towards organic reactions, speed, yield and efficiency. Subsequently, these catalysts minimize activation energy. In this context, we calculated the thermodynamic properties of these reactions for normal conditions in the presence and absence of the catalyst. Values of energy barriers of $\mathrm{Ta}, \mathrm{Tb}$ and $\mathrm{Tc}$ compounds in the absence and in the presence of $\mathrm{TiCl}_{4}$ and $\mathrm{Et}_{2} \mathrm{AlCl}$ catalyst at $25^{\circ} \mathrm{C}$ are given in Table 5 .

In case $\mathrm{A}$, when the catalyst is coordinated by the oxygen atom $\left(\mathrm{O}_{11}\right)$, we have remarked that IMDA

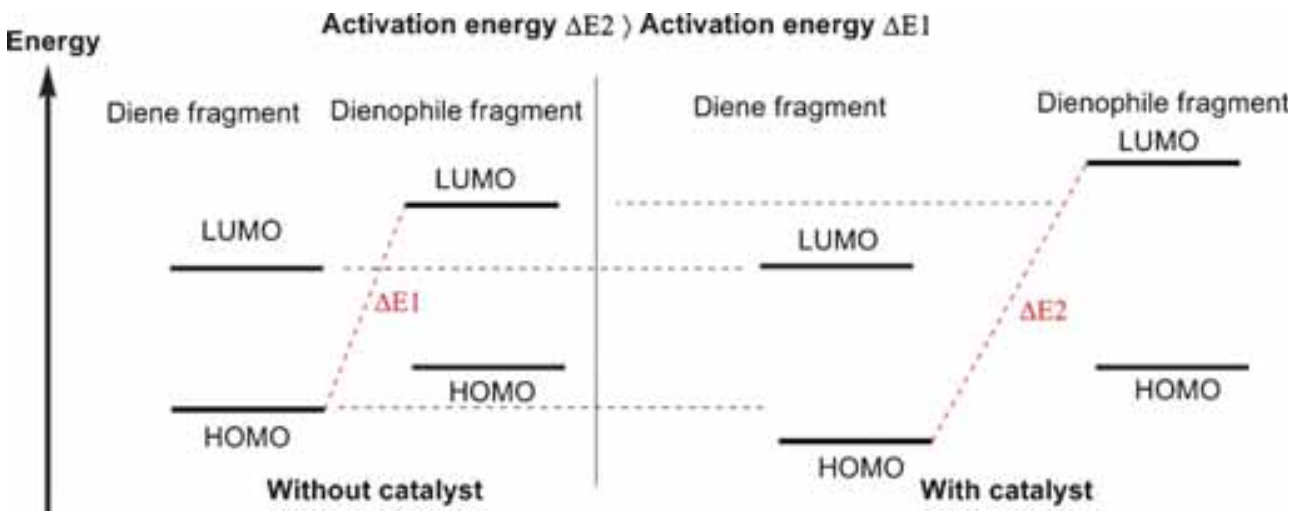

Figure 2. The activation energy diagrams in the presence and in the absence of the catalyst.

Table 6. Local electrophilicity $\omega(\mathrm{eV})$ and local nucleophilicity $\mathrm{N}(\mathrm{eV})$ of active centre sites.

\begin{tabular}{|c|c|c|c|c|c|c|c|c|}
\hline & & \multirow[b]{2}{*}{ k } & \multicolumn{2}{|c|}{$\mathrm{Ta}$} & \multicolumn{2}{|c|}{$\mathrm{Tb}$} & \multicolumn{2}{|c|}{ Tc } \\
\hline & & & $\omega_{\mathrm{k}}$ & $\mathrm{N}_{\mathrm{k}}$ & $\omega_{\mathrm{k}}$ & $\mathrm{N}_{\mathrm{k}}$ & $\omega_{\mathrm{k}}$ & $\mathrm{N}_{\mathrm{k}}$ \\
\hline \multirow[t]{12}{*}{ CASE A } & \multirow[t]{4}{*}{ W.C. } & 1 & 0.112 & 0.601 & 0.133 & 0.620 & 0.124 & 0.610 \\
\hline & & 4 & 0.092 & 0.239 & 0.082 & 0.213 & 0.083 & 0.211 \\
\hline & & 7 & 0.162 & -0.121 & 0.129 & -0.119 & 0.111 & -0.109 \\
\hline & & 8 & 0.109 & 0.111 & 0.060 & 0.119 & 0.067 & 0.084 \\
\hline & \multirow{4}{*}{$\mathrm{TiCl}_{4}$} & 1 & 0.284 & 0.263 & 0.226 & 0.291 & 0.277 & 0.212 \\
\hline & & 4 & 0.127 & 0.199 & -0.120 & 0.191 & -0.800 & 0.276 \\
\hline & & 7 & -0.087 & 0.028 & -0.182 & 0.005 & -0.664 & 0.186 \\
\hline & & 8 & 0.101 & 0.079 & 0.116 & 0.026 & 0.113 & 0.063 \\
\hline & \multirow[t]{4}{*}{$\mathrm{Et}_{2} \mathrm{AlCl}$} & 1 & 0.301 & 0.211 & 0.273 & 0.223 & 0.236 & 0.193 \\
\hline & & 4 & 0.122 & -0.016 & 0.070 & -0.009 & 0.072 & -0.029 \\
\hline & & 7 & -0.030 & -0.088 & -0.029 & -0.099 & 0.019 & -0.093 \\
\hline & & 8 & 0.071 & 0.063 & 0.062 & 0.083 & 0.019 & 0.080 \\
\hline \multirow[t]{12}{*}{ CASE B } & \multirow[t]{4}{*}{ W.C. } & 1 & 0.112 & 0.602 & 0.133 & 0.620 & 0.124 & 0.610 \\
\hline & & 4 & 0.096 & 0.238 & 0.082 & 0.213 & 0.084 & 0.211 \\
\hline & & 7 & 0.162 & -0.121 & 0.129 & 0.119 & 0.111 & 0.109 \\
\hline & & 8 & 0.109 & 0.111 & 0.060 & 0.119 & 0.067 & 0.084 \\
\hline & \multirow[t]{4}{*}{$\mathrm{TiCl}_{4}$} & 1 & 0.313 & 0.181 & 0.374 & 0.171 & 0.310 & 0.231 \\
\hline & & 4 & -0.177 & 0.074 & -0.132 & 0.027 & -0.004 & 0.282 \\
\hline & & 7 & -0.182 & 0.001 & -0.192 & 0.004 & 0.112 & 0.112 \\
\hline & & 8 & 0.114 & 0.109 & 0.162 & 0.123 & 0.100 & 0.071 \\
\hline & \multirow[t]{4}{*}{$\mathrm{Et}_{2} \mathrm{AlCl}$} & 1 & 0.263 & 0.321 & 0.221 & 0.268 & 0.273 & 0.327 \\
\hline & & 4 & 0.182 & 0.010 & 0.120 & 0.126 & 0.113 & 0.060 \\
\hline & & 7 & 0.092 & -0.097 & 0.073 & -0.096 & 0.081 & -0.111 \\
\hline & & 8 & 0.106 & 0.077 & 0.070 & 0.077 & 0.014 & 0.120 \\
\hline
\end{tabular}


reaction is delayed. This is confirmed by values of increased enthalpy and Gibbs free energy of reaction. There is also an increase of activation energy $\left(\mathrm{E}_{\mathrm{a}}\right)$ at $25^{\circ} \mathrm{C}$. For that reason, these systems need more energy compared to uncatalyzed systems. This means that IMDA reaction of the studied systems is disadvantaged at this temperature in this case. Otherwise, for case B, when catalyst is coordinated by nitrogen atom $\left(\mathrm{N}_{9}\right)$, we have shown that the energy barriers and free enthalpy of reaction are greater than $0(\Delta \mathrm{G}>0$ and $\Delta H>0)$, which means that IMDA reaction is not possible in this case.

Consequently, IMDA reaction of triene-amide catalysed by $\mathrm{TiCl}_{4}$ and $\mathrm{Et}_{2} \mathrm{AlCl}$ in ambient temperature, no acceleration or improved selectivity. On the contrary, IMDA reaction is disadvantaged because the coordination was done with atoms having the biggest nucleophilicity of diene fragment and not with the dienophile fragment. Lowering of the nucleophilicity in diene fragment, and thus HOMO (diene)-LUMO (dienophile) difference becomes very large and the activation energy becomes higher, which is shown schematically in Figure 2.

\subsection{Effect of Lewis acid on the local electrophilic and nucleophilic groups of active centre sites}

In order to confirm the results revealed in Tables 2, 3 and 4, we calculated the local nucleophilicity and electrophilicity groups of active centre sites (1, 4, 7 and 8). The results are given in Table 6 .

In Table 6, we notice that the nucleophilicity of centres (1) and (4) of diene fragment are observed to decrease by comparing with the results for uncatalyzed systems. This decrease corresponds to an increase in electrophilicity. Therefore, centres (7) and (8) of dienophile fragment are known to decrease both electrophilicity and nucleophilicity groups when using $\mathrm{TiCl}_{4}$ and $\mathrm{Et}_{2} \mathrm{AlCl}$ catalysts. Changes in active site characters (decrease in nucleophilicity of 1 and 4 sites in diene fragment) and decrease in electrophilicity of 7 and 8 sites in dienophile fragment) affect chemical reactivity, negatively and greatly. This conceptual DFT study showed that Lewis acid is unsuccessful to improve or increase speed, yield and efficiency of the IMDA reaction.

\section{Conclusions}

This study was conducted to estimate the effect of Lewis acids $\mathrm{TiCl}_{4}$ and $\mathrm{Et}_{2} \mathrm{AlCl}$ on the intramolecular Diels-Alder reaction of triene amide (Ta, Tb and $\mathrm{Tc}$ ) compounds, and to know their capacity and efficiency on the chemical reactivity. The study was performed at all susceptible sites to coordinate with Lewis acids (oxygens of ester group, carbonyl and nitrogen of amide group). A study through the polar model of Domingo showed that the oxygen and nitrogen atoms having lone pairs of amide group are the preferred coordination sites for Lewis acid due to their high nucleophilicity. The results showed that the nucleophilicity and electrophilicity of fragments and active sites are reduced in the presence of these catalysts and consequently, the chemical reactivity is diminished. In parallel, the thermochemistry studies demonstrated, on the one hand, when Lewis acid is coordinated to the oxygen atom, IMDA reaction is delayed. On the other hand, when Lewis acid is coordinated to the nitrogen atom, the IMDA reaction is not possible.

\section{References}

1. Yates P and Eaton P 1960 J. Am. Chem. Soc. 824436

2. Kagan H B and Riant O 1992 Chem. Rev. 921007

3. Pindur U, Lutz G and Otto C 1993 Chem. Rev. 93741

4. Birney D M and Houk K N 1990 J. Am. Chem. Soc. 112 4127

5. Yamabe S, Dai T and Minato T 1995 J. Am. Chem. Soc. 11710994

6. Sbai A, Branchadell V, Ortuño R M and Oliva A 1997 J. Org. Chem. 623049

7. Garcia J I, Martinez-Merino V, Mayoral J A and Salvatella L 1998 J. Am. Chem. Soc. 1202415

8. Yambe S and Minato T $2000 \mathrm{~J}$. Org. Chem. 651830

9. Alves C N, Carneiro A S, Andrés J and Domingo L R 2006 Tetrahedron 625502

10. Xia Y, Yin D, Rong C, Xu Q and Liu S 2008 J. Phys. Chem. A. 1129970

11. Geerlings P, Proft F D and Langenaeker W 2003 Chem. Rev. 1031793

12. Chattaraj P K, Sarkar U and Roy D R 2006 Chem. Rev. 1062065

13. Domingo L R, Asensio A and Arroyo P 2002 J. Phys. Org. Chem. 15660

14. Domingo L R and Sáez J A 2009 J. Org. Biomol. Chem. 73576

15. Ess D H, Jones G O and Houk K N 2006 Adv. Synth. Catal. 3482337

16. Garmes H 1995 In Triene-amides synthesis from homoallylic azides, Diels-Alder cycloaddition Thesis (El Jadida: Chouaib Doukkali University)

17. Benallou A, Garmes $\mathrm{H}$ and El Alaoui El Abdallaoui $\mathrm{H}$ 2014 Mor. J. Chem. 2181

18. Benallou A, Garmes $\mathrm{H}$ and El Alaoui El Abdallaoui H 2016 Tetrahedron 7276

19. Benallou A, Garmes H and El Alaoui El Abdallaoui H 2014 IJIAS 8685

20. Becke A D 1993 J. Chem. Phys. 985648 
21. Hehre W J, Radom L, Schleyer P von R and Pople J A (Eds.) 1986 In Ab Initio Molecular Orbital Theory (New York: Wiley)

22. Schlegel H B 1982 J. Comput. Chem. 3214

23. Frisch M J, Trucks G W, Schlegel H B, Scuseria G E, Robb M A, Cheeseman J R, Scalmani G, Barone V, Mennucci B, Petersson G A, Nakatsuji H, Caricato M, Li X, Hratchian H P, Izmaylov A F, Bloino J, Zheng G, Sonnenberg J L, Hada M, Ehara M, Toyota K, Fukuda R, Hasegawa J, Ishida M, Nakajima T, Honda $\mathrm{Y}$, Kitao O, Nakai $\mathrm{H}$, Vreven $\mathrm{T}$, Montgomery $\mathrm{J}$ A, Peralta J E, Ogliaro F, Bearpark M, Heyd J J, Brothers E, Kudin K N, Staroverov V N, Kobayashi R, Normand J, Raghavachari K, Rendell A, Burant J C, Iyengar S S, Tomasi J, Cossi M, Rega N, Millam J M, Klene M, Knox J E, Cross J B, Bakken V, Adamo C, Jaramillo J, Gomperts R, Stratmann R E, Yazyev O, Austin A J, Cammi R, Pomelli C, Ochterski J W, Martin R L, Morokuma K, Zakrzewski V G, Voth G A, Salvador P, Dannenberg J J, Dapprich S, Daniels A D, Farkas O, Foresman J B, Ortiz J V, Cioslowski J and Fox D J 2009 In Gaussian, Revision A.02 (Wallingford CT: Gaussian Inc.)
24. Parr R G, Szentpaly L V and Liu S 1999 J. Am. Chem. Soc. 1211922

25. Parr R G and Pearson R G 1983 J. Am. Chem. Soc. 105 7512

26. Domingo L R and Pérez P 2011 Org. Biomol. Chem. 9 7168

27. Kohn W and Sham L J 1965 Phys. Rev. 1401133

28. Domingo L R and Săez J A 2009 Org. Biomol. Chem. 7 3576

29. Yang W and Mortier W J 1986 J. Am. Chem. Soc. 108 5708

30. Soto-Delgado J, Domingo L R and Contreras R 2010 Org. Biomol. Chem. 83678

31. Reed A E, Weinstock R B and Weinhold F 1985 J. Chem. Phys. 83735

32. Snider B B and Ron E 1985 J. Am. Chem. Soc. 107 8160

33. Singleton D A and Hang C $2000 \mathrm{~J}$. Org. Chem. 65895

34. Loncharich R J and Houk K N 1987 J. Am. Chem. Soc. 1096947

35. Domingo L R, Chamorro E and Pérez P 2008 J. Org. Chem. 734615 